\title{
The impact of patient-prosthesis mismatch on late outcomes after mitral valve replacement
}

\author{
Buu-Khanh Lam, MD, Vincent Chan, MD, Paul Hendry, MD, Marc Ruel, MD, Roy Masters, MD, Pierre Bedard, MD, \\ Bill Goldstein, MD, Fraser Rubens, MD, and Thierry Mesana, MD
}

See related editorial on page 1405.

Supplemental material is available online.
From the Division of Cardiac Surgery, University of Ottawa Heart Institute, Ottawa, Ontario, Canada.

Read at the Eighty-sixth Annual Meeting of The American Association for Thoracic Surgery, April 29-May 2, 2006, Philadelphia, Pa.

Received for publication May 29, 2006; revisions received Nov 28, 2006; accepted for publication Dec 12, 2006.

Address for reprints: Buu-Khanh Lam, MDCM, Division of Cardiac Surgery, University of Ottawa Heart Institute, 40 Ruskin St, H3404, Ontario, Canada K1Y 4W7 (E-mail: bklam@ottawaheart.ca).

J Thorac Cardiovasc Surg 2007;133:1464-73 $0022-5223 / \$ 32.00$

Copyright $\odot 2007$ by The American Association for Thoracic Surgery

doi:10.1016/j.jtcvs.2006.12.071
Objectives: The incidence of patient-prosthesis mismatch after mitral valve replacement and its effect on late outcomes have remained unclear. This study was conducted to determine the impact of patient-prosthesis mismatch on recurrent congestive heart failure, postoperative pulmonary hypertension, and late survival after mitral valve replacement.

Methods: Between 1985 and 2005, 884 patients, with a mean age $63 \pm 12$ years, underwent mitral valve replacement (657 mechanical, 227 bioprosthesis) with contemporary prostheses. Mean clinical and echocardiographic follow-up was $5.1 \pm$ 4.1 years (4344 patient-years). Patient-prosthesis mismatch was defined as an indexed effective orifice area of $1.25 \mathrm{~cm}^{2} / \mathrm{m}^{2}$ or less. Parametric and nonparametric analyses were used to determine predictors of outcomes.

Results: The incidence of patient-prosthesis mismatch was 32\%. Predictors of recurrent congestive heart failure included low indexed effective orifice area, low ejection fraction, elevated postoperative mean mitral gradient, and use of a bioprosthesis $(P \leq .05)$. Postoperative pulmonary hypertension was associated with small mitral size, elevated mean mitral gradient, low ejection fraction, and atrial fibrillation $(P \leq .05)$; indexed effective orifice area did not predict postoperative pulmonary hypertension $(P=.89)$. Poor late survival was predicted by low indexed effective orifice area $\left(\leq 1.25 \mathrm{~cm}^{2} / \mathrm{m}^{2}\right)$, New York Heart Association class 3 or 4 , elevated right ventricular pressure, stroke, older age, coronary artery disease, and bioprosthesis use $(P \leq .05)$. Survival for patients with patient-prosthesis mismatch versus those without patient-prosthesis mismatch at $1,3,5$, and 10 years was $91 \%$ versus $95 \%, 85 \%$ versus $90 \%, 78 \%$ versus $86 \%$, and $65 \%$ versus $75 \%$, respectively $(P=.05)$.

Conclusions: Patient-prosthesis mismatch after mitral valve replacement is not uncommon; it is associated with recurrence of congestive heart failure and postoperative pulmonary hypertension and independently affected late survival. This study emphasizes the importance of implanting a sufficiently large prosthesis in adult patients undergoing mitral valve replacement.

$\mathrm{T}$ he concept of patient-prosthesis mismatch (PPM) was first described by Rahimtoola ${ }^{1}$ more than a quarter of a century ago. Since that time, the deleterious effects of PPM on left ventricular remodeling, functional status, and early and late survivals after aortic valve replacement have been extensively reported. ${ }^{2-9}$

Recently, there has been increasing interest in mitral valve patient-prosthesis mismatch (MVPPM), which has been described less often in adults but is commonly encountered in the pediatric population. ${ }^{10-12}$ MVPPM was identified in case report ${ }^{13}$ but has subsequently been more clearly defined using echocardiographic parameters as an indexed effective orifice area (IEOA) of 1.2 to $1.3 \mathrm{~cm}^{2} / \mathrm{m}^{2}$ or less. ${ }^{14,15}$ The 


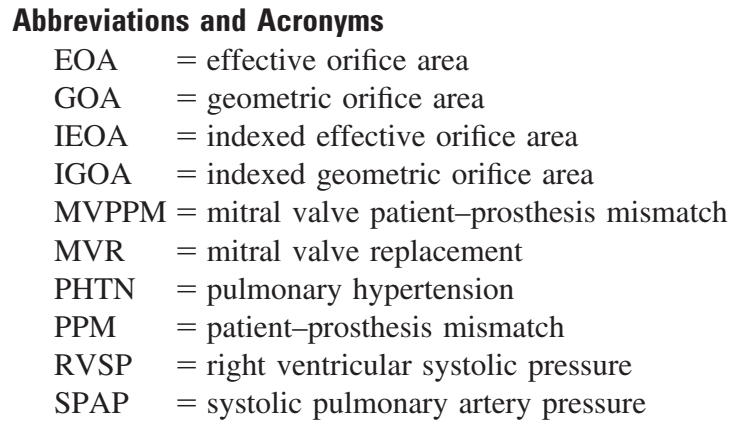

clinical problems associated with adult MVPPM have not been detailed but seem to include postoperative pulmonary hypertension (PHTN) and increased early mortality, although the latter has been disputed. ${ }^{16-18}$

The objectives of this study were to determine (1) the incidence of MVPPM and (2) the impact MVPPM on recurrent congestive heart failure (CHF), postoperative PHTN, and late survival.

\section{Materials and Methods}

\section{Patients}

Between 1985 and 2005, 884 patients, with a mean age of $63 \pm 12$ years (range 20-90 years, median 65 years), underwent mitral valve replacement (MVR) at the University of Ottawa Heart Institute. The methods of data collection and analysis of the University of Ottawa Heart Institute Valve Clinic database were reviewed and approved by the University of Ottawa Heart Institute Human Research Ethics Board. Patient demographics and characteristics are outlined in Table 1.

Standard surgical techniques were used, including cardiopulmonary bypass, mild systemic hypothermia, and access through a median sternotomy. Cardioplegic arrest was achieved with blood cardioplegia or a modified St Thomas crystalloid cardioplegic solution. Valve sizing and prosthesis brand selection were performed in accordance with guidelines provided by the manufacturers and at the discretion of the surgeon. The valves implanted included On-X (Medical Carbon Research Institute, Austin, Tex), St Jude Medical (St Jude Medical Inc, St Paul, Minn), Carbomedics (Sorin Biomedica, Via Crescentino, Italy), Medtronic Hall (Medtronic, Minneapolis, Minn), Carpentier-Edwards Perimount (Edwards Lifesciences, Irvine, Calif), and Medtronic Hancock II (Medtronic) (Table 2). Concomitant coronary artery bypass grafting was performed when indicated.

TABLE 1. Patient characteristics

\begin{tabular}{|c|c|c|c|c|}
\hline Characteristic & $\begin{array}{c}\text { All } \\
\mathrm{n}=884(\%)\end{array}$ & $\begin{array}{l}\text { NO MVPPM } \\
\mathrm{n}=604(\%)\end{array}$ & $\begin{array}{c}\text { MVPPM } \\
n=280(\%)\end{array}$ & $\boldsymbol{P}$ \\
\hline \multicolumn{5}{|l|}{ Demography } \\
\hline Female & $521(59)$ & $381(73)$ & $140(27)$ & .0002 \\
\hline Age $(y$, mean $\pm S D)$ & $63 \pm 12$ & $63 \pm 12$ & $65 \pm 11$ & .08 \\
\hline Body surface area $\left(\mathrm{m}^{2}\right)$ & $1.8 \pm 0.2$ & $1.7 \pm 0.2$ & $1.9 \pm 0.2$ & $<.0001$ \\
\hline $\mathrm{EOA}\left(\mathrm{cm}^{2}\right)$ & $2.6 \pm 0.6$ & $2.8 \pm 0.5$ & $2.1 \pm 0.2$ & $<.0001$ \\
\hline IEOA $\left(\mathrm{cm}^{2} / \mathrm{m}^{2}\right)$ & $1.5 \pm 0.4$ & $1.6 \pm 0.3$ & $1.1 \pm 0.1$ & $<.0001$ \\
\hline \multicolumn{5}{|l|}{ Cardiac comorbidity } \\
\hline Atrial fibrillation & $323(37)$ & $248(41)$ & $76(27)$ & $<.0001$ \\
\hline Previous cardiac surgery & $145(16)$ & $112(19)$ & $33(12)$ & .03 \\
\hline CAD & $300(34)$ & $192(29)$ & $108(39)$ & .05 \\
\hline NYHA class III and IV & $525(59)$ & $368(61)$ & $157(56)$ & .06 \\
\hline LV class III and IV & $212(24)$ & $149(25)$ & $63(23)$ & .1 \\
\hline Mitral stenosis & $371(42)$ & $262(44)$ & $109(39)$ & .3 \\
\hline Mitral regurgitation & $248(28)$ & $157(26)$ & $91(33)$ & .04 \\
\hline Mix stenosis/regurgitation & $265(30)$ & $187(31)$ & $78(28)$ & .4 \\
\hline \multicolumn{5}{|l|}{ Associated procedure } \\
\hline CABG & $263(30)$ & $156(26)$ & $107(38)$ & .002 \\
\hline 1 & $99(11)$ & $59(10)$ & 40 (14) & \\
\hline 2 & $81(9)$ & $52(8)$ & $29(10)$ & \\
\hline$>3$ & $83(10)$ & $45(8)$ & $38(14)$ & \\
\hline \multicolumn{5}{|l|}{ IEOA $\left(\mathrm{cm}^{2} / \mathrm{m}^{2}\right)$} \\
\hline$<1.25$ & 0 & $280(32)$ & $129(57)$ & $<.0001$ \\
\hline $1.26-1.50$ & $289(33)$ & 0 & $41(18)$ & $<.0001$ \\
\hline $1.51-1.75$ & $123(14)$ & 0 & $51(23)$ & $<.0001$ \\
\hline $1.76-2.0$ & $106(12)$ & 0 & $4(2)$ & $<.0001$ \\
\hline$>2.0$ & $86(9)$ & 0 & $2(1)$ & $<.0001$ \\
\hline
\end{tabular}

$E O A$, Effective orifice area; IEOA, indexed effective orifice area; $C A D$, coronary artery disease; $N Y H A$, New York Heart Association; $L V$, left ventricle; $C A B G$, coronary artery bypass grafting; $S D$, standard deviation; MVPPM, mitral valve patient-prosthesis mismatch. 
TABLE 2. Prostheses implanted with respective effective orifice areas and indexed effective orifice areas

\begin{tabular}{|c|c|c|c|c|c|c|}
\hline & $\begin{array}{c}\text { EOA }\left(\mathrm{cm}^{2}\right) / I E O A \\
\left(\mathrm{~cm}^{2} / \mathrm{m}^{2}\right) \\
n(\%)\end{array}$ & Size 25 & Size 27 & Size 29 & Size 31 & Size 33 \\
\hline \multirow[t]{2}{*}{ Mechanical } & 657 & 46 & 116 & 202 & 192 & 101 \\
\hline & $2.5 / 1.41$ & $2.2 / 1.24$ & $2.4 / 1.46$ & $2.6 / 1.51$ & 2.6/1.46 & $2.7 / 1.35$ \\
\hline \multirow[t]{2}{*}{ On-X (Medical Carbon Research Institute, Austin, Tex) } & $85(13)$ & $33(72)$ & $29(25)$ & $2(1)$ & $16(8)$ & $5(5)$ \\
\hline & $2.4 / 1.30$ & $2.4 / 1.33$ & $2.4 / 1.39$ & $2.4 / 1.37$ & $2.4 / 1.31$ & $2.4 / 1.11$ \\
\hline \multirow[t]{2}{*}{ Carbomedics (Sorin Biomedica, Via Crescentino, Italy) } & $121(18)$ & 0 & $15(13)$ & $42(21)$ & $39(20)$ & $25(25)$ \\
\hline & $2.3 / 1.26$ & $2.4 /--$ & $2.4 / 1.39$ & $2.3 / 1.28$ & $2.2 / 1.19$ & $2.3 / 1.17$ \\
\hline \multirow[t]{2}{*}{ Medtronic-Hall (Medtronic, Minneapolis, Minn) } & $242(37)$ & $9(19)$ & $36(31)$ & $89(44)$ & $77(40)$ & $31(30)$ \\
\hline & $3.1 / 1.78$ & $2.2 / 1.24$ & $2.7 / 1.72$ & $3.5 / 2.07$ & $3.5 / 1.97$ & $3.5 / 1.89$ \\
\hline Bioprosthesis & 227 & 17 & 47 & 81 & 60 & 22 \\
\hline \multirow[t]{2}{*}{ Medtronic Hancock II (Medtronic) } & $203(89)$ & $17(100)$ & $34(72)$ & $70(86)$ & $60(100)$ & $22(100)$ \\
\hline & $2.1 / 1.22$ & $1.5 / 0.90$ & $1.8 / 1.09$ & $1.9 / 1.11$ & $2.8 / 1.56$ & 2.6/1.42 \\
\hline
\end{tabular}

$E O A$, Effective orifice area; IEOA, indexed effective orifice area.

\section{Follow-up}

The University of Ottawa Heart Institute Valve Clinic prospectively follows all surgical valve recipients. At each annual visit, all patients underwent a medical history focused on the determination of functional status and the occurrence of valve-related complications, a physical examination, laboratory testing (complete blood count, chemistry, international normalized ratio), electrocardiogram, and chest radiography. Prosthesis-related complications were recorded according to the Guidelines for Reporting Morbidity and Mortality after Cardiac Valvular Operations. ${ }^{19}$ The mean follow-up was $5.1 \pm 4.1$ years (4344 patient-years, median 3.8 years, maximum 19 years) and complete.

In addition, 746 patients (84\%) underwent a complete M-mode, 2-dimensional, and Doppler transthoracic echocardiogram at their first annual follow-up appointment and subsequently as clinically indicated per the recommendations of the American College of Cardiology/American Heart Association/American Society of Echocardiography 2003 Guideline Update for the Clinical Application of Echocardiography. ${ }^{20}$ Postoperative follow-up transthoracic echocardiographic recordings of systolic pulmonary artery pressure (SPAP) were available on a subset of 518 patients (59\%). Cardiac dimensions, gradients, and estimation of right ventricular systolic pressure (RVSP) and SPAP were assessed with continuouswave Doppler. For SPAP, the maximum peak TR velocity (V) recorded from any view was used to determine the RVSP with the simplified Bernoulli equation (RVSP $=4 \mathrm{~V}^{2}+$ radial artery pressure), with radial artery pressure assumed to be $10 \mathrm{~mm} \mathrm{Hg}$. SPAP was assumed to equate the RVSP in the absence of pulmonary stenosis and right ventricular outflow tract obstruction. The mean interval to the follow-up echocardiograms was $5.2 \pm 3.7$ years (range 0.5-19 years, median 5.1 years).
Mitral Valve Patient-Prosthesis Mismatch Definition

The calculation of the indexed valve area has been somewhat controversial. Some reports have used the geometric orifice area $(\mathrm{GOA})^{17,18}$ provided by the manufacturer as a base value, whereas other reports have used the effective orifice area (EOA) measured in vivo. ${ }^{14,15}$ To avoid confusion, the indexed valve area will be referred to specifically as indexed GOA (IGOA) or IEOA. In this study, we used the latter method because of its known clinical correlation with clinical outcomes and more accurate estimation of postoperative gradients. ${ }^{21}$ The IEOA was obtained by dividing the valve's in vivo EOA (centimeters squared), provided by the manufacturer or obtained from the literature, by the patient's calculated body surface area (meters squared). When more than 1 EOA was available, the mean value was used in the calculation of IEOA. By using these criteria and the work by $\mathrm{Li}$ and colleagues, ${ }^{16}$ in which MVPPM was defined as an IEOA of 1.2 to $1.3 \mathrm{~cm}^{2} / \mathrm{m}^{2}$ or less, we defined MVPPM as any IEOA of 1.25 $\mathrm{cm}^{2} / \mathrm{m}^{2}$ or less. The selection of this value was also based on the lack of clinical effect in our statistical modeling with IEOA values of 1.5 $\mathrm{cm}^{2} / \mathrm{m}^{2}, 1.4 \mathrm{~cm}^{2} / \mathrm{m}^{2}$, and $1.3 \mathrm{~cm}^{2} / \mathrm{m}^{2}$.

\section{Definition of Outcomes}

Primary outcomes in this study included (1) the recurrence of CHF as defined by New York Heart Association functional class 3 or 4 for more than 4 consecutive weeks or death where the primary contributing diagnosis was CHF; (2) postoperative PHTN as an SPAP greater than $40 \mathrm{~mm} \mathrm{Hg}$ as measured by echocardiography; ${ }^{22}$ and (3) late survival as a patient censored at a minimum of 30 days after surgery.

\section{Data Analysis}

Descriptive statistics were used to summarize data. Categoric data were described using frequencies and percentages; comparisons 
were made using the chi-square test or the Fisher exact test when the frequency was less than 5. Continuous variables were presented as mean \pm standard deviation, and comparisons of continuous variables were performed using the Student $t$ test for normally distributed data and the Wilcoxon rank-sum test when values were skewed. Exploratory correlation analyses were performed using the Spearman $\left(r_{s}\right)$ correlation coefficient.

The Kaplan-Meier method was used to assess time-related outcomes (freedom from $\mathrm{CHF}$, freedom from postoperative PHTN, and survival). Predictors of outcomes were identified using a semiparametric multivariable Cox proportional hazard model; variables screening ensured that an adequate $(n=10)$ number of events were associated with a potential risk factor and that the scales of ordinal and continuous variables were calibrated with respect to outcome. Variable selection proceeded in a forward stepwise manner with a liberal entry criterion of $P$ less than .1 and a stay criterion of $P$ equal to or less than .05 . Logistic regression was applied to determine the effect of valve type (mechanical, bioprosthesis), valve size criteria (manufacturer size, calculated IEAO), and echocardiographic parameters (mean and peak mitral gradients, SPAP) on the cumulative rate of recurrent $\mathrm{CHF}$ and postoperative PHTN. All time-related estimates are considered reliable to 10 years. All analyses were performed using the SAS statistical software (SAS v9.1; SAS, Cary, NC).

\section{Results}

Mitral Valve Patient-Prosthesis Mismatch

There were 280 patients (32\%) with an IEOA of 1.25 $\mathrm{cm}^{2} / \mathrm{m}^{2}$ or less, meeting the definition of MVPPM (Table 1). The proportion of patients with MVPPM was lower in those with mechanical valves than those with bioprostheses (23\% vs $57 \%, P<.0001)$. A higher proportion of patients with mechanical valves had an IEOA greater than $1.50 \mathrm{~cm}^{2} / \mathrm{m}^{2}$ (39\% vs $26 \%, P<.0001$ ).

\section{Outcomes}

Recurrence of congestive heart failure. The overall freedom from recurrence of $\mathrm{CHF}$ at 1, 3, 5, and 10 years was 98\%, 96\%, 94\%, and 85\%, respectively (Figure E1). In patients with MVPPM, 1, 3, 5, and 10-year rates were significantly less than patients without MVPPM $(\mathrm{P}<$ .0001) (Figure 1, A). Predictors of recurrent CHF included low IEOA ( $\leq 1.0$ and $\leq 1.5 \mathrm{~cm}^{2} / \mathrm{m}^{2}$, hazard ratio [HR] 4.0 , 1.6-10.4, and 3.5, 1.9-6.3), worse left ventricular function (HR 1.01, 1.0-1.03), elevated mean mitral gradient on follow-up echocardiography (HR 2.0, 1.1-3.3), and prolonged cardiopulmonary bypass (HR 1.1, 1.01-1.1) (Table E1). Coronary artery disease, age, and peak mitral gradients on follow-up did not predict the return of $\mathrm{CHF}(P>.05)$. There was a linear effect of MVPPM (odds ratio [OR] 3.9), postoperative mitral gradients (OR 1.8), use of a bioprosthesis (OR 2.7), and elevated SPAP (OR 1.02) on the recurrence of CHF (Appendix E1).

Postoperative pulmonary hypertension. Exploratory correlation matrices demonstrated an absence of linear re- lationships between IEOA and mean mitral gradient, peak mitral gradient, and SPAP. In patients with MVPPM (IEAO $\leq 1.25 \mathrm{~cm}^{2} / \mathrm{m}^{2}$ ), there was no correlation between IEOA and mean and peak gradients, or with SPAP; however, a strong correlation was observed between peak mitral gradient and SPAP. In patients with an IEOA of $1.0 \mathrm{~cm}^{2} / \mathrm{m}^{2}$ or less, IEOA correlated well with mean and peak mitral gradients but not with SPAP. In general, elevated postoperative mean and peak mitral gradients were closely related to SPAP. In patients with bioprostheses, a linear relationship was seen between IEAO and mean mitral gradients, but not peak mitral gradients or SPAP.

Freedom from PHTN at 1, 3, 5, and 10 years was 99\%, 96\%, 93\%, and 78\%, respectively (Figure E2). Freedom from postoperative PHTN in patients with MVPPM at 1, 3, 5 , and 10 years was similar to that of patients without MVPPM (98\% vs $99 \%, 97 \%$ vs $96 \%, 96 \%$ vs $92 \%$, and $69 \%$ vs $78 \%$, respectively, $P=.6$ ); however, patients with smaller sized valves $(\leq 27)$ had higher rates of postoperative PHTN when compared with patients with valve sizes 29 or larger $(P=.005)$ (Figure $1, B)$.

Predictors of postoperative PHTN included older age (HR 1.02, 1.01-1.02), smaller valve size (HR 1.04, 1.011.07), low ejection fraction (HR 1.03, 1.01-1.05), elevated postoperative mitral gradient (HR 1.15, 1.09-0.121), atrial fibrillation (HR 1.31, 1.12-1.52), and use of a bioprosthesis (HR 1.36, 1.12-1.64) (Table E1); IEOA of $1.25 \mathrm{~cm}^{2} / \mathrm{m}^{2}$ or less did not predict postoperative PHTN (HR 1.02, 0.84-1.3).

Survival. Overall 1, 3, 5, and 10-year survivals were $95 \%, 90 \%, 85 \%$, and $73 \%$, respectively (Figure E3). Patients with MVPPM had worse 1, 3, 5, and 10-year survivals (91\% vs $95 \%, 85 \%$ vs $90 \%, 78 \%$ vs $86 \%$, and $65 \%$ vs $75 \%$, respectively, $P=.05$ ) (Figure $1, C$ ). Survival in patients with elevated SPAP $(>40 \mathrm{~mm} \mathrm{Hg})$ was less than their counterparts with SPAP in the normal range $(P=.02)$ (Figure E4).

Predictors of survival included older age (HR 1.10, 1.041.34), IEOA of $1.25 \mathrm{~cm}^{2} / \mathrm{m}^{2}$ or less (HR 2.4, 1.5-3.9), preoperative CHF (HR 1.22, 1.05-1.42), presence of coronary artery disease (HR 23, 3.0-175), history of stroke (HR 3.7, 1.6-8.3), postoperative PHTN as defined by elevated SPAP (HR 1.1, 1.03-1.09), and implantation of a bioprosthesis (HR 2.5, 1.3-4.7). No significant difference in survival was seen between patients with an IEOA between 1.01 and $1.25 \mathrm{~cm}^{2} / \mathrm{m}^{2}$ versus an IEOA of 1.0 $\mathrm{cm}^{2} / \mathrm{m}^{2}$ or less $(P=.17)$.

\section{Discussion}

The key findings of this retrospective study were as follows: (1) The incidence of MVPPM was higher than originally anticipated; (2) MVPPM was associated with recurrence of CHF; (3) MVPPM was not directly associated with postop- 


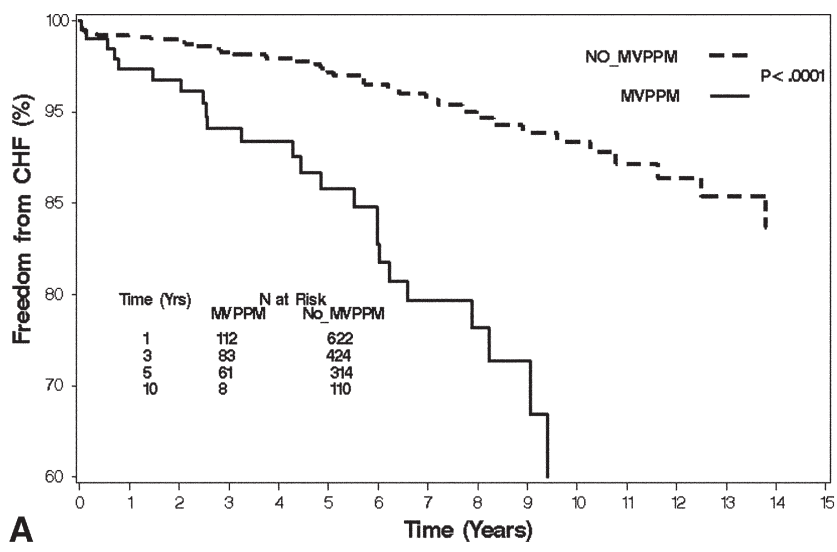

Figure 1. A, Freedom from recurrent CHF: MVPPM versus NOMVPPM $(P<$ .0001 ). B, Cumulative incidence of postoperative PHTN: smaller sized valve $(\leq 27)$ versus larger $(\geq 29)$ sized valve $(P$ $=.005)$. C, Adjusted survival according to MVPPM versus NOMVPPM $(P=.05)$. CHF, Congestive heart failure; PHTN, pulmonary hypertension; MVPPM, mitral valve patient-prosthesis mismatch.
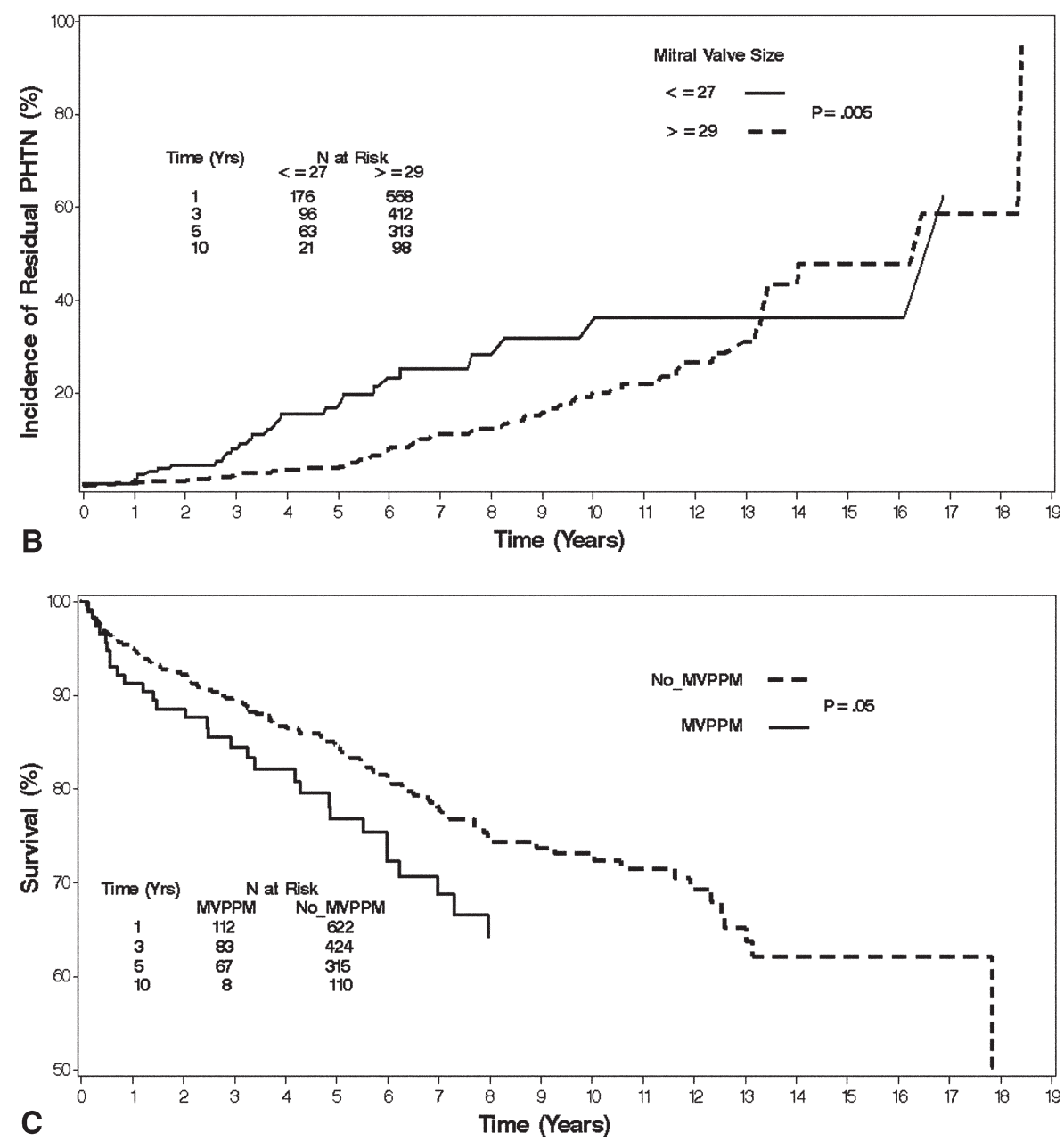

erative PHTN, but smaller valve size and elevated gradients were directly associated with postoperative PHTN; and (4) survival of patients post-MVR was affected by MVPPM.

The concept of residual obstruction with persistent elevated transprosthetic gradients postaortic valve replacement was first reported by Rahimtoola in $1978 .{ }^{1}$ Since then, many significant contributions have led to the establishment of precise diagnostic criteria and to the development of preventative strategies to avoid PPM in the context of aortic valve replacement. ${ }^{21,23}$ The negative effects of aortic valve PPM on left ventricular remodeling, functional status, early mortality, and late survival have been extensively corroborated. ${ }^{2-9}$ What remains uncertain is whether clinically deleterious effects of PPM could be encountered after MVR. 


\section{Mitral Valve Patient-Prosthesis Mismatch}

There has been a recent mounting interest in MVPPM, which has been well documented in the pediatric population. In the latter, mitral valve re-replacement rates upward of $27 \%$ have been reported because somatic growth has led many children to outgrow their mitral valve prosthesis. ${ }^{10,12}$ A variety of factors have been used in an attempt to define the concept of clinical MVPPM in childre: These have included size/weight ratios, $Z$ scores, maximum transprosthesis velocity (Vmax), and 2.5 times increase in body weight from the time of implant. In all instances, these factors have been correlated with outcomes (early mortality, survival, and PHTN). ${ }^{10-12}$

Adult MVPPM was the subject of an original case report in $1981 ;{ }^{13}$ it has subsequently been theorized, through in vitro pulse duplicator analysis, that an IGOA less than 1.3 to $1.5 \mathrm{~cm}^{2} / \mathrm{m}^{2}$ could potentially leave the patient with high postoperative transprosthetic gradients unrelated to structural dysfunction. ${ }^{14}$ In a clinical study, a good correlation between elevated transprosthetic mitral gradient and in vivo IEOA was demonstrated by the use of the continuity equation during echocardiographic assessment of porcine mitral prostheses. ${ }^{15}$ In this report, an IEOA of 1.3 to $1.5 \mathrm{~cm}^{2} / \mathrm{m}^{2}$ or less at rest was associated with a mean mitral gradient of 4 $\mathrm{mm} \mathrm{Hg}$; with every $10 \%$ increase in stroke volume (maximum 50\%), there was a proportional increase of the mean mitral gradient $\left(\mathrm{eg}\right.$, IEOA $\leq 1.0 \mathrm{~cm}^{2} / \mathrm{m}^{2},+50 \%$, mean mitral gradient of $14 \mathrm{~mm} \mathrm{Hg}$ ). In our study, we had an incidence of MVPPM (IEOA $\leq 1.25 \mathrm{~cm}^{2} / \mathrm{m}^{2}$ ) of $32 \%$ with $5 \%$ of patients having an IEOA less than $1.0 \mathrm{~cm}^{2} / \mathrm{m}^{2}$.

\section{Mitral Valve Patient-Prosthesis Mismatch and Congestive Heart Failure Recurrence}

The unadjusted 1,5, and 10-year cumulative incidence of recurrent CHF post-MVR was $2 \%, 6 \%$, and $15 \%$, respectively; the rates were significantly higher $(5 \%, 15 \%$, and $38 \%$, respectively) when adjusted for MVPPM criteria. These results are similar to those we previously reported and take into further consideration the indexed in vivo EOA rather than only prosthesis size. ${ }^{24} \mathrm{CHF}$ was 3.5 and 4 times more likely to develop postoperatively in patients with an IEAO of $1.0 \mathrm{~cm}^{2} / \mathrm{m}^{2}$ or less and an IEAO of $1.25 \mathrm{~cm}^{2} / \mathrm{m}^{2}$ or less, respectively. Elevated mean mitral gradients were associated with recurrence of CHF. Although an IEOA of 1.25 $\mathrm{cm}^{2} / \mathrm{m}^{2}$ or less and elevated mean mitral gradients predicted the recurrence of $\mathrm{CHF}$, no direct significant correlation was established between these 2 variables $\left(\mathrm{r}_{\mathrm{s}}=-0.12, P=.1\right)$. This finding was in contrast with work from Dumesnil and colleagues ${ }^{15}$ and $\mathrm{Li}$ and colleagues ${ }^{16}$ that described a moderate level of correlation between IEOA and transprosthetic gradients $(r=0.46-0.63)$. This weaker correlation could be due to the smaller proportion of patients with prostheses less than $27 \mathrm{~mm}\left(26 \%\right.$ vs $52 \%{ }^{16}$ and $\left.69 \%{ }^{15}\right)$ observed in our study; this could considerably decrease the risk of elevated transprosthetic gradients developing in patients and thereby impacting the establishment of a correlation. A second potential reason for this would be the dependency of transprosthetic gradients on transvalvular flow rate, a dependent factor of diastolic filling time, which is in return sensitive to the effect of chronotropy. In this context, the establishment of good correlations between IEOA and transprosthetic gradients is more difficult post-MVR than aortic valve replacement.

In our study, in view of the high proportion of patients (76\%) with class I and II left ventricular function preoperatively, the effect of left ventricular function on recurrence of CHF was noted as marginal (HR 1.01). As in patients with aortic valve PPM, we must not discount the potential impact of left ventricular function on outcomes post-MVR. ${ }^{3,25}$

Postoperative PHTN was weakly associated with the recurrence of CHF; overall, the mean SPAP of patients with CHF was greater than that of their counterparts $(47.6 \pm 11.3$ vs $42.8 \pm 13.4 \mathrm{~mm} \mathrm{Hg}, P=.04)$. In patients with recurrent CHF, there was no correlation between IEOA and SPAP $(P=.6)$. The known detrimental impact of residual or recurrent PHTN, due to mitral valve disease, on functional outcome and survival has been reported. ${ }^{25-28}$

\section{Mitral Valve Patient-Prosthesis Mismatch and Postoperative Pulmonary Hypertension}

The unadjusted 1, 5, and 10-year cumulative incidence of postoperative PHTN was $1 \%, 7 \%$, and $22 \%$, respectively; once adjusted for smaller mitral valve size $(\leq 27)$, the rates were higher in patients with size 25 and 27 prostheses at 1 , 5 , and 10 years $(2 \%$ vs $1 \%, 18 \%$ vs $4 \%, 33 \%$ vs $20 \%$, respectively, $P=.005$ ). When we looked at 1,5 , and 10 -year rates of postoperative PHTN in patients with MVPPM versus NOMVPPM, there was no difference (2\% vs $1 \%, 4 \%$ vs $8 \%, 31 \%$ vs $22 \%$, respectively, $P=.6$ ). These results sharply contrasted with those reported by $\mathrm{Li}$ and colleagues, ${ }^{16}$ showing a postoperative PHTN prevalence rate of 68\% in patients with MVPPM. This difference, along with the lack of correlation between IEOA and SPAP $\left(\mathrm{r}_{\mathrm{s}}=\right.$ $0.03, P=.4$ ), could be attributable to several factors: First, the proportion of patients in our study who received smaller sized prostheses (25 and 27) was 26\% (mechanical 25\%, bioprosthesis $28 \%$ ) in comparison with the $52 \%$ reported. This might constitute an unusually elevated proportion by current standards. $^{24,29,30}$ This would mean that 29 of the 56 patients in Li and colleagues' study were already at a higher risk of having MVPPM and postoperative PHTN; this was confirmed by the elevated incidence of MVPPM (71\%). Second, the population selected by $\mathrm{Li}$ and coworkers, because of the greater proportion of smaller valves, would take longer to normalize any preoperative PHTN and would therefore be subject to higher postoperative SPAP, especially in patients with MVPPM, thus possibly strengthening 
the correlation between IEOA and SPAP that the authors described. In contrast, our patients had an almost equal proportion of patients with PHTN irrespective of MVPPM adjustments (57\% vs $55 \%, P=.2)$. Third, there is the issue of body surface area; the mean body surface area of our patients without MVPPM was $1.76 \pm 0.18 \mathrm{~m}^{2}$, a number almost equivalent to $\mathrm{Li}$ and colleagues' group of patients with MVPPM $\left(1.75 \pm 0.16 \mathrm{~m}^{2}\right)$. This would lead us to conclude that a significant proportion of patients with borderline body surface area likely did not receive a valve sufficiently large enough, thus predisposing them to MVPPM. Finally, a point of concern is the fact that the rate of postoperative PHTN was observed to be increasing over time, leading us to question the exact contribution of other confounders (age, atrial fibrillation, type of prosthesis, and left ventricular function).

The IEAO was not predictive of postoperative PHTN, but its surrogate marker (valve size $\leq 27$ ) and elevated mean mitral gradients were. This lack of correlation could be explained by the incomplete reporting of SPAP in the echocardiograms collected. In a similar analysis in children, Masuda and colleagues ${ }^{12}$ reported the absence of correlation between IGOA and catheterized pulmonary artery wedge pressure; however, good correlation was seen between maximal transprosthetic flow velocity (Vmax) and IGOA and between Vmax and catheterized pulmonary artery wedge pressure. It has been postulated that MVPPM post-MVR may predispose one to persistence of high afterload on the right ventricle, resulting in stunning and right ventricular failure leading to increased early mortality. ${ }^{17}$ This may be extrapolated to patients with MVPPM and a chronic decline of right ventricular function over time, which would ultimately lead to right ventricular failure and death.

In view of the relative inconsistency of the relationships between PHTN markers (SPAP, IEOA, Vmax, pulmonary wedge pressure, transprosthetic gradients, and pulmonary vascular resistance and compliance) reported here and in the literature, further data are required to elucidate the potential mechanistic and hemodynamic ramifications of PHTN postMVR and its impact on clinical outcomes.

\section{Mitral Valve Patient-Prosthesis Mismatch and Survival}

The overall survival for our cohort of patients post-MVR was acceptable and approached $75 \%$ at 10 years. The 1,5 , and 10-year survivals for patients with MVPPM were significantly worse than those of their counterparts. Fernandez and coworkers ${ }^{18}$ were among the first to report on the clinical implications of MVPPM; however, in their study, the GOA, which often overestimates the valve area, was used to calculate the IGOA. They did not find any association between indexed valve area and early and late morbidity or late mortality. A second report by Yazdanbakhsh and colleagues ${ }^{17}$ on the impact of IGOA on outcomes stated that the lower tail end of IGOA $\left(\leq 1.9 \mathrm{~cm}^{2} / \mathrm{m}^{2}\right)$ was associated with early mortality (HR 4.3, 1.6-9.5) but had no effect on late mortality. Once again, the GOA was used in the calculations of IGOA and may have led to overestimation of IGOA and thus biased the effect of the latter on late mortality. In our study, an IEOA of $1.25 \mathrm{~cm}^{2} / \mathrm{m}^{2}$ or less was a predictor of poor late survival. As previously stated, we believe that the IEOA is a better prognostic indicator than the IGOA because it has been shown to be a reliable predictor of clinical outcomes. ${ }^{21}$ We must caution that, as is the case in most retrospective studies, a finding of association does not automatically imply causation. The presence of other significant clinical correlates (age, coronary artery disease, left ventricular function, preoperative $\mathrm{CHF}$, and PHTN) to survival would indicate a multifactorial cause that will require further elucidation.

\section{Limitations}

This is a single-institution, nonrandomized, observational clinical study in which group differences and known confounders were controlled for in the multivariable analysis. Despite the large sample size and statistical adjustments applied, unmeasured and unknown confounders may have influenced the results. Nonsystematic echocardiographic follow-up of patients represents an important limitation of this study because missing echocardiographic data (echocardiographic predictors of MVPPM) may have had an important impact on clinical outcomes. In addition, an underreporting of SPAP on follow-up echocardiograms may have resulted in an underpowered assessment of correlation between IEOA and PHTN.

We have made all efforts to use primarily only published EOAs rather than GOAs in the calculation of IEOA values. However, because of the limited availability of reports on mitral EOAs for all of the valve types and brands, we did not discriminate against EOA values obtained by the pressure half-time method; this latter is known to overestimate EOAs. When an EOA for a particular valve brand and size was not available, we had to use the GOA. These 2 conditions may have led to an underestimation of the true incidence of MVPPM in this cohort of patients.

Furthermore, Cox proportional hazards models require an assumption of independent censoring that may not always be met. In this regard, it is possible that patients lost to follow-up after a number of visits may have had subsequent outcomes that were not accounted for in the analyses. Similar to that of other observational cohorts, the results of these analyses may not be generalizable to all patients who have undergone prosthetic valve replacement at other centers.

Finally, as mentioned previously, in view of the relative inconsistency and scarce amount of information on the relationships between PHTN markers (SPAP, IEOA, Vmax, pulmonary wedge pressure, transprosthetic gradients, pul- 
monary vascular resistance, and compliance), further data will be required to elucidate the potential mechanistic and hemodynamic ramifications of PHTN post-MVR.

\section{Conclusions}

Our results suggest that a threshold exists below which outcomes are negatively impacted by the insertion of a smaller than acceptable valve; however, contrary to aortic valve PPM, there are limited operative solutions to alleviate the problem of MVPPM. Possible alternatives, such as stentless mitral prostheses and homografts, require expertise and experience, thus limiting their use in this context. Surgeons would be best served to be aware of this to guide valve selection toward the largest available EOA valve for annulus size, irrespective of valve type or brand; this latter point is even more important when implanting a bioprosthesis, which we have observed to be more prone to MVPPM. Finally, this study reemphasizes the importance of mitral valve repair as the preferred therapeutic option whenever possible.

This study constitutes an initial report associating IEOA post-MVR and clinical outcomes (recurrent CHF, postoperative PHTN, and late survival). By using an IEOA of 1.25 $\mathrm{cm}^{2} / \mathrm{m}^{2}$ or less as a cutoff point to define MVPPM, we demonstrated that the incidence of MVPPM was higher than anticipated. We also determined that patients with MVPPM were 4 times more likely to experience recurrent CHF. MVPPM was also associated with postoperative PHTN (SPAP $>40 \mathrm{~mm} \mathrm{Hg}$ ), although smaller valve size rather than IEAO was a predictor of PTHN. Finally, MVPPM was associated with a decrease in late survival.

\section{References}

1. Rahimtoola SH. The problem of valve prosthesis-patient mismatch. Circulation. 1978;58:20-4.

2. Blais C, Dumesnil JG, Baillot R, Simard S, Doyle D, Pibarot P. Impact of valve prosthesis-patient mismatch on short-term mortality after aortic valve replacement. Circulation. 2003;108:983-8.

3. Pibarot P, Dumesnil JG, Lemieux M, Cartier P, Mqtras J, Durand LG. Impact of prosthesis-patient mismatch on hemodynamic and symptomatic status, morbidity and mortality after aortic valve replacement with a bioprosthetic heart valve. J Heart Valve Dis. 1998;7:211-8.

4. Rao V, Jamieson WRE, Ivanov J, Armstrong S, David TE. Prosthesispatient mismatch affects survival after aortic valve replacement. Circulation. 2000;102(19 Suppl 3):III5-9.

5. Ruel M, Rubens FD, Masters RG, Pipe AL, Bqdard P, Hendry PJ, et al. Late incidence and predictors of persistent or recurrent heart failure in patients with aortic prosthetic valves. J Thorac Cardiovasc Surg. 2004;127:149-59.

6. Tasca G, Brunelli F, Cirillo M, Dallatomba M, Mhagna Z, Troise G, et al. Impact of valve prosthesis-patient mismatch on left ventricular mass regression following aortic valve replacement. Ann Thorac Surg. 2005;79:505-10.

7. Mohty-Echahidi D, Malouf JF, Girard SE, Schaff HV, Grill DE, Enriquez-Sarano ME, et al. Impact of prosthesis-patient mismatch on long-term survival in patients with small St Jude Medical mechanical prostheses in the aortic position. Circulation. 2006;113:420-6.

8. Tasca G, Mhagna Z, Perotti S, Centurini PB, Sabatini T, Amaducci A, et al. Impact of prosthesis-patient mismatch on cardiac events and midterm mortality after aortic valve replacement in patients with pure aortic stenosis. Circulation. 2006;113:570-6.
9. Pibarot P, Blais C, Dumesnil JG, Baillot R, Simard S, Doyle D. Impact of valve prosthesis-patient mismatch on short-term mortality after aortic valve replacement. Circulation. 2003;108:983-8.

10. Caldarone CA, Raghuveer G, Hills CB, Atkins DL, Burns TL, Behrendt DM, et al. Long-term survival after mitral valve replacement in children aged $<5$ years: a multi-institutional study. Circulation. 2001;104(12 Suppl 1):I143-7.

11. Friedman S, Edmunds LH Jr, Cuaso CC. Long-term mitral valve replacement in young children. Influence of somatic growth on prosthetic valve adequacy. Circulation. 1978;57:981-6.

12. Masuda M, Kado H, Tatewaki H, Shiokawa Y, Yasui H. Late results after mitral valve replacement with bileaflet mechanical prosthesis in children: evaluation of prosthesis-patient mismatch. Ann Thorac Surg. 2004;77:913-7.

13. Rahimtoola SH, Murphy E. Valve prosthesis-patient mismatch. A long-term sequela. Br Heart J. 1981;45:331-5.

14. Dumesnil JG, Yoganathan AP. Valve prosthesis hemodynamics and the problem of high transprosthetic pressure gradients. Eur J Cardiothorac Surg. 1992;6(Suppl 1):S34-7.

15. Dumesnil JG, Honos GN, Lemieux M, Beauchemin J. Validation and applications of mitral prosthetic valvular areas calculated by Doppler echocardiography. Am J Cardiol. 1990;65:1443-8.

16. Li M, Dumesnil JG, Mathieu P, Pibarot P. Impact of valve prosthesispatient mismatch on pulmonary arterial pressure after mitral valve replacement. J Am Coll Cardiol. 2005;45:1034-40.

17. Yazdanbakhsh AP, van den Brink RBA, Dekker E, de Mol BAJM. Small valve area index: its influence on early mortality after mitral valve replacement. Eur J Cardiothoracic Surg. 2000;17:222-7.

18. Fernandez J, Chen C, Laub GW, Andersen WA, Brdlik OB, Murphy $\mathrm{MM}$, et al. Predictive value of prosthetic valve area index for early and late clinical results after valve replacement with the St Jude Medical valve prosthesis. Circulation. 1996;94(9 Suppl):II109-12.

19. Edmunds LH, Clark RE, Cohn LH, Grunkemeier GL, Miller C, Weisel RD. Guidelines for reporting morbidity and mortality after cardiac valvular operations. Ann Thorac Surg. 1996;62:932-5.

20. Cheitlin MD, Armstrong WF, Aurigemma GP, Beller GA, Bierman FZ, Davis JL, et al. ACC/AHA/ASE 2003 Guideline Update for the Clinical Application of Echocardiography: summary article. A report of the American College of Cardiology/American Heart Association Task Force on Practice Guidelines (ACC/AHA/ASE Committee to Update the 1997 Guidelines for the Clinical Application of Echocardiography). J Am Soc Echocardiogr. 2003;16:1091-110.

21. Pibarot P, Dumesnil JG. Prosthesis-patient mismatch: definition, clinical impact, and prevention. Heart. 2006;92:1022-9. Epub 2005 Oct 26.

22. McQuillan BM, Picard MH, Leavitt M, Weyman AE. Clinical correlates and reference intervals for pulmonary artery systolic pressure among echocardiographically normal subjects. Circulation. 2001;104: 2797-802.

23. Pibarot P, Dumesnil JG, Cartier PC, Mqtras J, Lemieux MD. Patientprosthesis mismatch can be predicted at the time of operation. Ann Thorac Surg. 2001;71(5 Suppl):S265-8.

24. Ruel M, Rubens FD, Masters RG, Pipe AL, Bedard P, Mesana TG. Late incidence and predictors of persistent or recurrent heart failure in patients with mitral prosthetic valves. J Thorac Cardiovasc Surg. 2004;128:278-83.

25. Crawford MH, Souchek J, Oprian CA, Miller DC, Rahimtoola S, Giacomini JC, et al. Determinants of survival and left ventricular performance after mitral valve replacement. Circulation. 1990;81:1173-81.

26. Leavitt JI, Coats MH, Falk RH. Effects of exercise on transmitral gradient and pulmonary artery pressure in patients with mitral stenosis or a prosthetic mitral valve: a Doppler echocardiographic study. J Am Coll Cardiol. 1991;17:1520-6.

27. Song JK, Kang DH, Lee CW, Lee SG, Cheong SS, Hong MK, et al. Factors determining the exercise capacity in mitral stenosis. Am J Cardiol. 1996;78:1060-2.

28. Vincens JJ, Temizer D, Post JR, Edmunds J, Herrmann HC. Long-term outcome of cardiac surgery in patients with mitral stenosis and severe pulmonary hypertension. Circulation. 1995;92(9 Suppl):II137-42. 
29. Crawford J. Residual pulmonary artery hypertension after mitral valve replacement: size matters! J Am Coll Cardiol. 2005;45:1041-2.

30. Ikonomidis JS, Kratz JM, Crumbley III AJ, Stroud MR, Bradley SM, Sade RM, et al. Twenty-year experience with the St Jude Medical mechanical valve prosthesis. J Thorac Cardiovasc Surg. 2003;126: 2022-31.

\section{Discussion}

Dr F. Crawford (Charleston, SC): Drs Feindel and Mitchell, I have no conflicts to disclose. I enjoyed this presentation very much. PPM after aortic valve replacement has been discussed at length in recent years, although there is far from universal agreement about the potential implications of such mismatch. Far less information is available about PPM in the mitral position. Several important differences between the aortic and mitral position exists as indicated by the authors, including limited options for implanting large valves in the mitral positions and inferior types of prostheses available for MVR. In addition, PPM in the aortic position may adversely affect left ventricular function, whereas in the mitral position it is usually right ventricular function that is affected.

In this excellent article that describes a large series of patients who underwent MVR and were followed prospectively by the authors, IEOA did not predict persistent PHTN, which has generally been considered an important factor predicting outcomes after MVR. I have several questions for the authors.

If PHTN was not associated with PPM, what do you postulate is the reason for the poorer outcomes in your patients?

Second, what percentage of your patients had chordal-sparing MVR, and was the lack of such a chordal-sparing procedure an independent risk factor for poorer outcomes?

Finally, in the article you state, "We recommend avoidance of a bioprosthesis in patients with possible MVPPM criteria." Does this mean that you would therefore recommend using a mechanical prosthesis in such a patient even if the patient were elderly and that you therefore believe the potential risk of MVPPM in such a patient outweighs the known risk of long-term anticoagulation with Coumadin?

Dr Lam: With regard to the lack of correlation between the IEOA and PHTN in this study, I must say that although our follow-up is prospective in nature and we gather as many echocardiograms as we can, when we look at the data with regard to the availability of the SPAP, these are not always reported consistently in all of our echocardiogram reports. Therefore, we are likely underpowered to detect the link between IEOA and PHTN. This would mean that some of our patients, who had lower IEOAs or EOAs, likely did not have the PHTN variable available for analysis.

With regard to the possible explanations as to why patients with PHTN do not fare as well; it is difficult to explain. I think that, at this point, the correlation between IEOA and other echocardiographic markers, such as gradients or PHTN, remains unclear in the literature. Some studies have found correlations, and others have not. At this point I can't tell you for sure what would be an adequate marker to be associated with a worse IOA, whether it can be the gradients, PHTN, or aortic valve compliance. The latter has been suggested as a newer potential clinical marker that could be monitored. Once these markers are established, we still have to correlate them with clinical outcomes.
With regard to your question on chordal preservation, this study is somewhat historical in nature and spans 20 years. Certainly our practice currently is to do chordal preservation, but that has changed over the years and that data are not entirely available in all patients, so therefore I am not able to answer that question.

With regard to the use of biological valves, I think that we currently abide by all the guidelines with regard to the use of an appropriate valve for the patient size and risk factors. There are various sizes in terms of valves, and each valve brand has an EOA that is variable. I think the take-home message is that we should try and insert the largest EOA valve possible irrespective of brand, and that varies from one brand name to the other. Certainly we would not subject a patient to the undo risk of anticoagulation if we found an adequate sized biological valve for the annulus.

Dr R. Martinez-Sanz (Tenerife, Spain): In mitral insufficiency when a mitral ring is performed, the aim is to reduce the posterior annulus, undersizing this as much as $26 \mathrm{~mm}, 28 \mathrm{~mm}$, or less. For this reason, when mitral repair is not possible, we perform MVR using a 27- or 25-mm valve prosthesis with less hospital mortality and postoperative complications than when using a bigger prosthesis. Now we are studying the follow-up of this class of patients.

The question is, in your study, do you know how many patients with undersized prostheses there were?

Dr Lam: To answer your question, this table illustrates the in vivo EOA used in this study according to valve and valve size; as you can see, some of these valves, highlighted in green, have smaller EOAs to begin with. Once this is indexed, there is a variability with regard to each valve, and this is, of course, dependent on your patient population, but this is our patient population and what their index was. So the green areas are the areas of trouble, and we have noticed them in this type of valve, the bioprosthesis, and we have noticed them in the larger patients.

Now, the larger patients, one of the things that we do know is that the literature has few EOA publications and the sample sizes are relatively small. So we are going by a small number, but it seems to suggest that for the larger sized patients, the valves that are out there right now may not have an appropriately sized EOA, and that is what we found in our study.

Dr Martinez-Sanz: This is for the whole group, not for the mitral regurgitation group only?

Dr Lam: I unfortunately do not have data for the mitral regurgitation group specifically.

Dr E. Jamieson (Vancouver, Canada): Congratulations for bringing this topic forward. Some of my questions have been answered, but a couple are, how confident are you that a break-off of 1.25 does not require further investigation? The second has been partially answered by your last slide, but the other question is related to your large experience with the On-X valve. As we all know, the size of the orifice is $25 \mathrm{~mm}$ regardless of whether you are using a 25 or 31 ; how did you handle that and did you find any discrepancies in performance?

Dr Lam: With regard to the On-X valve, you are right, the valve in this scenario seemed to perform adequately except for the larger sized valves, and as I just mentioned, I think that this needs to be revisited in terms of an appropriately sized valve for a larger patient per se. We have done the analyses on various segments of IEOAs, going from 1.5 to $1.0 \mathrm{~cm}^{2} / \mathrm{m}^{2}$. Clinical correlations are strongest when you hit $1.0 \mathrm{~cm}^{2} / \mathrm{m}^{2}$. However, I think that in terms 
of clinical outcomes, the significant cutoff in this study was approximately $1.25 \mathrm{~cm}^{2} / \mathrm{m}^{2}$, and that is why we used the 1.25 $\mathrm{cm}^{2} / \mathrm{m}^{2}$. The range that is given in the literature varies from 1.2 to $1.5 \mathrm{~cm}^{2} / \mathrm{m}^{2}$, and that is based on pulse duplicator data on small sample sizes to establish echocardiographic correlations. To put that into a clinical context, we had to do the analysis over a wide range of IEOAs.

Dr Pasquale Totaro (Palermo, Italy): First of all, I congratulate you for addressing such an important issue that has been almost ignored for a long time. I have done a similar study, and I am going to present my results during an European meeting in due course. The data I am going to present are different from the data you presented today. By using only stented Carpentier-Edwards bioprosthesis and evaluating the PPM based on the postoperative in vivo IEOA, we found an incidence of PPM less than $10 \%$, and this included patients with a size 25 bioprosthesis.

Did you evaluate PPM on the basis of in vivo postoperative echocardiogram data on your patients? Did you find any difference between mechanical and biological prostheses?

Dr Lam: We have not performed the analysis yet, but the data are available. We didn't look at that specifically. We specifically looked at our MVPPMs and what their gradients were, but that is an excellent point.

I think that when you look at the data with regard to EOA, there are 2 ways to go about it: (1) Ask your echocardiographer to actually do the measurements by the continuity equation, not the pressure half time, which is not as reliable. (2) Review the literature and garner all the EOAs possible that were published based on in vivo echo measurements and not laboratory or pulse duplicator data, which are sometimes what you get when you get the little pamphlet from the companies giving you different EOAs. If the latter is what you have done, then we should probably have to compare our mutual results.

Dr Totaro: So these are not data that you calculated in vivo postoperatively?

Dr Lam: No. We used averaged EOAs from the studies in the literature.

Dr Totaro: I think that this could make a real impact and explain the difference between our results .

Dr Guo-Wei He (Hong Kong, China): Dr Lam, this is an important study, particularly, as Dr Crawford says, the mitral valve and the patient mismatch was not the same as the aortic valve and the patient mismatch. A few years ago we published a study in the Journal on aortic valve mismatch with patient body surface area, and what we found was with a body surface area more than 1.6, when you use a small aortic prosthesis, including a 19- and a 20-mm prosthesis, there was less long-term survival.

Your study is interesting and scientifically accurate, but in clinical practice to use your study to look at EOA is complicated for a practicing surgeon. Can you simplify your study to look at, when a patient's body surface area is more than $1.5,1.6,1.7$, and 1.8 , a small mitral size such as 25 plus 27 compared with the larger group? To simplify your results, can you do it that way, or maybe you have done that?

Dr Lam: That is definitely possible to do. We have the data set, and it wouldn't be out of the scope of the completion of this project. I think that in terms of clinical information it would be much easier to interpret, as you said, and that is something we will definitely look into. 
APPENDIX E1. Logistic regression analysis of valve parameter effects on congestive heart failure recurrence

\begin{tabular}{lccc}
\hline Factor & Coefficient \pm SD & $\boldsymbol{P}$ & Odds ratio (CL) \\
\hline IEAO $\leq 1.25 \mathrm{~cm}^{2} / \mathrm{m}^{2}$ & $1.4 \pm 0.29$ & $<.0001$ & $3.9(2.2-6.9)$ \\
Bioprosthesis implantation & $0.79 \pm 0.38$ & .04 & $2.7(1.1-6.5)$ \\
Elevated mean gradient & $0.61 \pm 0.26$ & .02 & $1.8(1.1-3.1)$ \\
Elevated SPAP & $0.02 \pm 0.01$ & .05 & $1.02(1.01-1.05)$
\end{tabular}

$S D$, Standard deviation; $C L$, confidence limit; IEAO, indexed effective orifice area; $S P A P$, systolic pulmonary artery pressure.
TABLE E1. Predictors of outcomes

\begin{tabular}{|c|c|c|}
\hline Factor & Coefficient \pm SD & $P$ \\
\hline \multicolumn{3}{|l|}{ Recurrent CHF } \\
\hline $\mathrm{IEOA}<1.0 \mathrm{~cm}^{2} / \mathrm{m}^{2}$ & $1.39 \pm 0.48$ & .004 \\
\hline IEOA $<1.25 \mathrm{~cm}^{2} / \mathrm{m}^{2}$ & $1.26 \pm 0.29$ & $<.0001$ \\
\hline Low EF & $0.02 \pm 0.001$ & .05 \\
\hline $\begin{array}{l}\text { Elevated mean } \\
\text { mitral gradient }\end{array}$ & $0.59 \pm 0.26$ & .02 \\
\hline Prolonged CPB & $0.01 \pm 0.003$ & .03 \\
\hline PHTN & $0.90 \pm 0.62$ & .14 \\
\hline $\begin{array}{l}\text { Elevated peak mitral } \\
\text { gradient }\end{array}$ & $0.04 \pm 0.07$ & .59 \\
\hline \multicolumn{3}{|l|}{ Postoperative PHTN } \\
\hline Older age & $0.02 \pm 0.003$ & $<.0001$ \\
\hline Smaller sized valve & $-0.04 \pm 0.02$ & .01 \\
\hline Low EF & $-0.06 \pm 0.03$ & .03 \\
\hline $\begin{array}{l}\text { Elevated mean } \\
\text { mitral gradient }\end{array}$ & $0.13 \pm 0.03$ & $<.0001$ \\
\hline Bioprosthesis & $0.31 \pm 0.09$ & .002 \\
\hline Atrial fibrillation & $-0.26 \pm 0.08$ & .0008 \\
\hline IEOA $<1.25 \mathrm{~cm}^{2} / \mathrm{m}^{2}$ & $0.02 \pm 0.1$ & .89 \\
\hline \multicolumn{3}{|l|}{ Survival } \\
\hline Older age & $0.20 \pm 0.05$ & .04 \\
\hline IEOA $<1.25 \mathrm{~cm}^{2} / \mathrm{m}^{2}$ & $0.87 \pm 0.25$ & .0005 \\
\hline $\begin{array}{l}\text { Preoperative NYHA } \\
\text { class } 3 \text { or } 4\end{array}$ & $0.21 \pm 0.08$ & .009 \\
\hline CAD & $3.14 \pm 1.03$ & .002 \\
\hline CVA & $1.30 \pm 0.41$ & .002 \\
\hline Prolonged CPB & $0.006 \pm 0.002$ & .003 \\
\hline PHTN & $-0.06 \pm 0.02$ & .0001 \\
\hline Bioprosthesis & $-0.90 \pm 0.33$ & .006 \\
\hline
\end{tabular}

IEOA, Indexed effective orifice area; $E F$, ejection fraction; $C P B$, cardiopulmonary bypass; PHTN, pulmonary hypertension; NYHA, New York Heart Association; $C A D$, coronary artery disease; $C V A$, cerebrovascular disease; $S D$, standard deviation. 


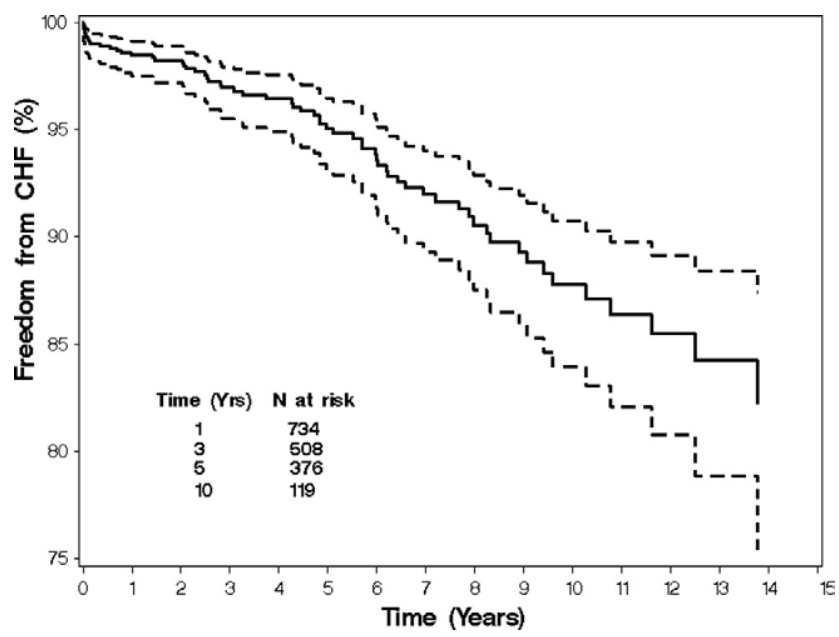

Figure E1. Freedom from recurrence of CHF. Mean (solid line) $\pm 95 \%$ confidence interval (CI) (dashed line). CHF, Congestive heart failure.

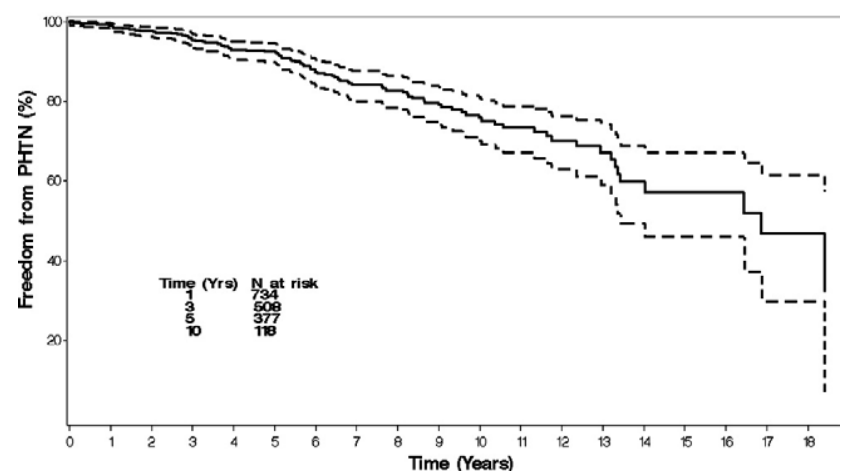

Figure E2. Freedom from postoperative PHTN. Mean (solid line) $\pm 95 \%$ Cl (dashed line). PHTN, Pulmonary hypertension.

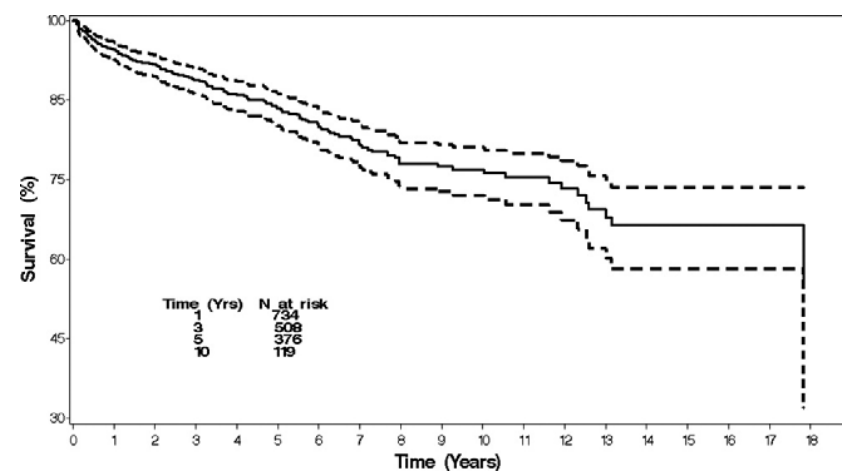

Figure E3. Overall survival. Mean (solid line) $\pm 95 \% \mathrm{CI}$ (dashed line). 


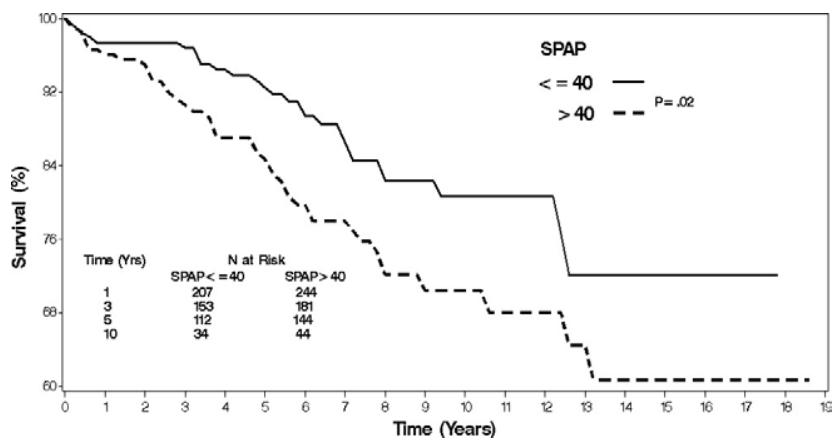

Figure E4. Adjusted survival according to high SPAP versus low SPAP $(P=.02) . S P A P$, Systolic pulmonary artery pressure. 